\title{
The Earth Surface Mineral Dust Source Investigation: An Earth Science Imaging Spectroscopy Mission
}

\author{
Robert O. Green ${ }^{1 *}$, Natalie Mahowald ${ }^{2}$, Charlene Ung ${ }^{1}$, David R. Thompson ${ }^{1}$, Lori Bator ${ }^{1}$, Matthew Bennet ${ }^{1}$, \\ Michael Bernas ${ }^{1}$, Natalie Blackway ${ }^{1}$, Christine Bradley ${ }^{1}$, Jeff Cha ${ }^{1}$, Pamela Clark ${ }^{1}$, Roger Clark ${ }^{3}$, Deborah \\ Cloud $^{1}$, Ernesto Diaz ${ }^{1}$, Eyal Ben Dor ${ }^{4}$, Riley Duren ${ }^{1}$, Michael Eastwood ${ }^{1}$, Bethany L. Ehlmann ${ }^{1,5}$, Lisa Fuentes ${ }^{1}$, \\ Paul Ginoux ${ }^{6}$, Johannes Gross ${ }^{1}$, Yutao He ${ }^{1}$, Olga Kalashnikova ${ }^{1}$, William Kert ${ }^{1}$, Didier Keymeulen ${ }^{1}$, Matt \\ Klimesh $^{1}$, Daniel Ku ${ }^{1}$, Helenann Kwong-Fu ${ }^{1}$, Elliott Liggett ${ }^{1}$, Longlie Li ${ }^{2}$, Sarah Lundeen ${ }^{1}$, Maciej D. \\ Makowski $^{1}$, Alan Mazer ${ }^{1}$, Ron Miller ${ }^{7}$, Pantazis Mouroulis ${ }^{1}$ Bogdan Oaida ${ }^{1}$, Greg S. Okin ${ }^{8}$, Alberto Ortega ${ }^{1}$, \\ Amalaye Oyake ${ }^{1}$, Hung Nguyen ${ }^{1}$, Theresa Pace ${ }^{1}$, Thomas H. Painter ${ }^{8}$, Jack Pempejian ${ }^{1}$, Carlos Perez Garcia- \\ Pando ${ }^{9}$, Thang Pham ${ }^{1}$, Benjamin Phillips ${ }^{10}$, Randy Pollock ${ }^{1}$, Richard Purcell ${ }^{1}$, Vincent Realmuto ${ }^{1}$, Josh \\ Schoolcraft ${ }^{1}$, Amit Sen ${ }^{1}$, Simon Shin ${ }^{1}$, Lucas Shaw ${ }^{1}$, Manny Soriano ${ }^{1}$, Gregg Swayze ${ }^{11}$, Erik Thingvold ${ }^{1}$, Afsheen \\ Vaid $^{1}$, Jason Zan ${ }^{1}$

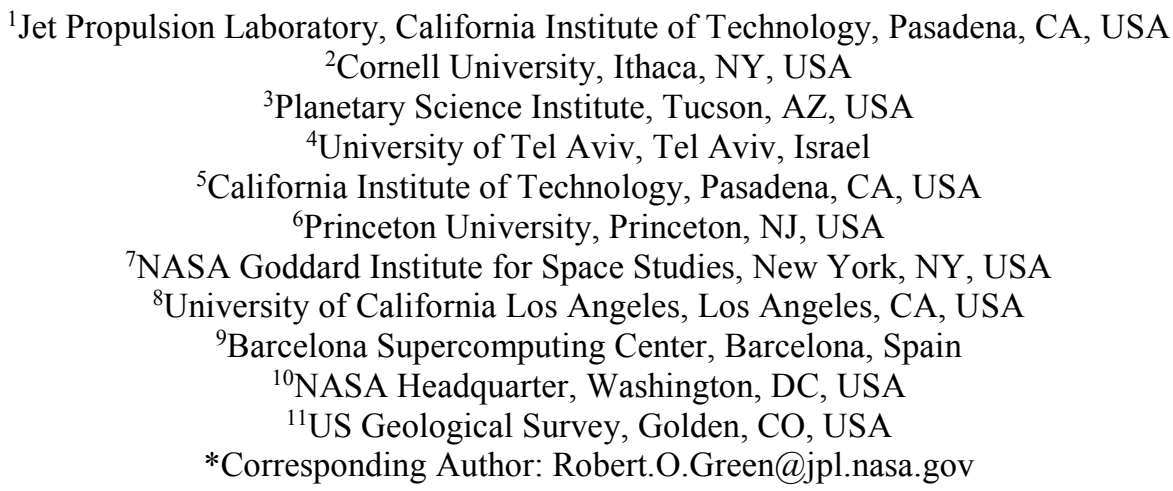

\begin{abstract}
The Earth Surface Mineral Dust Source Investigation, EMIT, is planned to operate from the International Space Station starting no earlier than the fall of 2021. EMIT will use visible to short wavelength infrared imaging spectroscopy to determine the mineral composition of the arid land dust source regions of the Earth to advance our knowledge of the radiative forcing effect of these aerosols. Mineral dust emitted into the atmosphere under high wind conditions is an element of the Earth system with many impacts to the Earth's energy balance, atmosphere, surface, and oceans. The Earth's mineral dust cycle with source, transport, and deposition phases are studied with advanced Earth System Models. Because the chemical composition, optical and surface properties of soil particles vary strongly with the mineral composition of the source, these models require knowledge of surface soil mineral dust source composition to accurately understand dust impacts on the Earth system now and in the future. At present, compositional knowledge of the Earth's mineral dust source regions from existing data sets is uncertain as a result of limited measurements. EMIT will use spectroscopically-derived surface mineral composition to update the prescribed boundary conditions for state-of-the-art Earth System Models. The EMIT-initialized models will be used to investigate the impact of direct radiative forcing in the Earth system that depends strongly on the composition of the mineral dust aerosols emitted into the atmosphere. These new measurements and related products will be used to address the EMIT science objectives and made available to the science community for additional investigations. An overview of the EMIT science, development, and mission is presented in this paper.
\end{abstract}

TABLE OF CONTENTS

1. INTRODUCTION ............................................................1

2. SCIENCE APPROACH...............................................2

3. KEY MISSION REQUIREMENTS ...............................4

4. INSTRUMENT DESIGN .............................................5

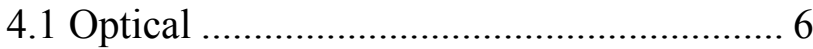

4.2 Mechanical................................................ 6

4.4 Electrical and Software.............................. 7

4.5 Thermal.................................................... 7

4.6 Integration, Test and Calibration ................ 8

5. Mission Elements \& PlanNed Operations ...8 6. SUMMARY AND CONCLUSIONS...............................11

ACKNOWLEDGMENTS........................................12

REFERENCES ............................................................12

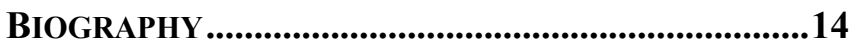

\section{INTRODUCTION}

The Earth has a mineral dust cycle that impacts many elements of the Earth system and is comprised of source, emission, transport, and deposition phases processes. Mineral dust plays a role in direct and indirect radiative forcing, 
weather, atmospheric chemistry, cryosphere melt and hydrology, biogeochemistry of ocean and terrestrial ecosystems, and can be a hazard to human populations. Figure 1-1 depicts key elements of the interaction of mineral dust aerosols with the Earth system. The primary focus of EMIT is the direct impact to radiative forcing. Figure 12 shows a satellite observation of mineral dust emitted into the atmosphere from the arid land regions of northern Libya.

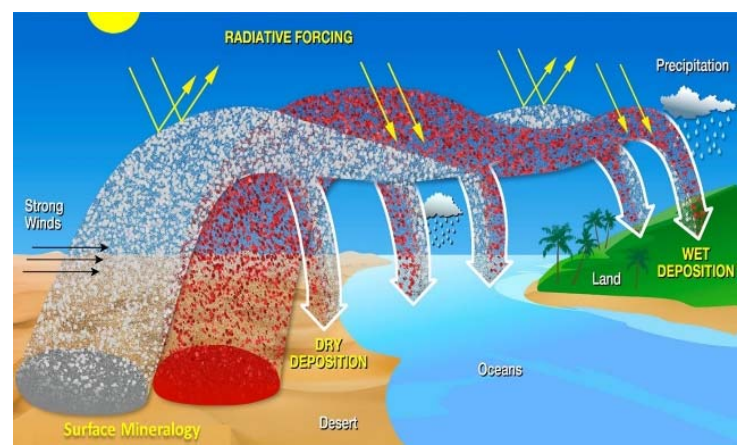

Figure 1-1. Depiction of the Earth's mineral dust cycle that is the focus of the NASA EMIT mission planned to begin operation from the ISS in 2021

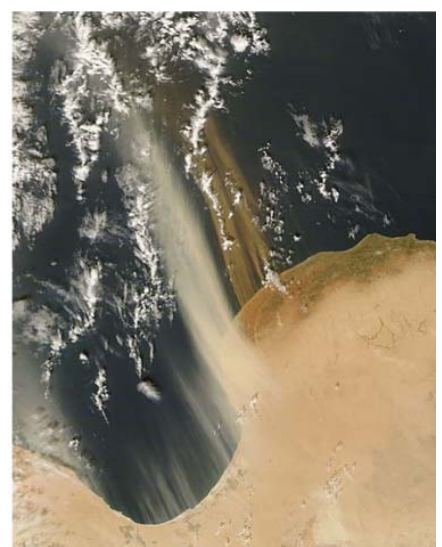

Figure 1-2. Satellite image of mineral dust of different compositions being emitted into the atmosphere. (Terra satellite, MODIS instrument, from northern Libya, September 28, 2010

The Intergovernmental Panel on Climate Change (IPCC) has identified mineral dust radiative forcing as a key uncertainty in the overall contributions of aerosols to radiative forcing in the Earth system (Boucher et al., 2013; Myhre et al., 2013). In the 5th Assessment Report, the global impact of mineral dust aerosols was estimated to have a slightly cooling effect. However, the uncertainty error bars are large enough to include the possibility of heating. Part of the uncertainty results from the common model assumption of dust aerosol composition and optical properties that are globally uniform, despite variations that are welldocumented (c.f. Figure 1-2).

Mineral dust is a key contributor to direct radiative forcing over arid regions, impacting agriculture, precipitation, and desert encroachment around the globe (Mahowald et al., 2010; Mahowald and Kiehl, 2003; Miller and Tegen, 1998; Rosenfeld et al., 2001; Yoshioka et al., 2007). The assumption of globally uniform dust properties also introduces regional errors into our estimation of these impacts that remain poorly understood due to uncertainties in the dust composition. Dust radiative forcing is highly dependent on its mineral-specific absorption properties (Scanza et al., 2015; Sokolik and Toon, 1999), and the current range of iron oxide abundance in dust source models $(0-7 \mathrm{wt} \%)$ (Claquin et al., 1999) translates into a $460 \%$ uncertainty in regional radiative forcing predicted by Earth System Models (ESMs). Currently, ESMs are being updated to model mineral dust sources of diverse composition (e.g. Scanza, et al., 2015) that are inferred from atlases of soil type (Claquin et al., 1999; and Journet et al., 2014). However, knowledge of global soil composition is based upon mineralogical analyses of fewer than 5000 soil samples from mostly agricultural regions rather than the arid and semi-arid regions emitting dust. This gap in knowledge of the arid land dust source mineral composition is contributing to the uncertainty in ESM related to mineral dust aerosols and their effects on the Earth system.

The EMIT mission is designed to close this gap by acquiring more than one billion direct observations of the Earth's arid and semi-arid mineral dust source regions. These high-fidelity spectroscopic observations will be analyzed to deliver new mineral composition products for the surface boundary conditions for the ESMs and to address the EMIT mission radiative forcing-related goals and objectives.

\section{SCIENCE APPROACH}

The goal of EMIT is to advance understanding of the Earth's mineral dust cycle and its impact on radiative forcing by using state-of-the-art ESMs 
that are initialized with more accurate measurements of mineral dust source composition. EMIT has two science objectives: The first is to constrain the sign and magnitude of the dust direct radiative forcing at regional and global scales. EMIT achieves this objective by acquiring, validating and delivering updates of surface mineralogy used to initialize ESMs. The second is to predict the increase or decrease of available dust sources under future climate scenarios. EMIT achieves this objective by initializing forecast models with the mineralogy of soils exposed within at-risk lands bordering arid dust source regions. These adjacent lands for future potential mineral dust sources are the sparsely vegetated lands within approximately $50 \mathrm{~km}$ of the current arid land dust source regions targeted by EMIT.

EMIT uses imaging spectroscopy in the Visible to Short Wavelength Infrared (VSWIR) portion of the spectrum from the International Space Station (ISS) to measure the arid land mineral dust source regions of the Earth, recording the distinct spectral features of the iron oxide, sulfate, clay, and carbonate minerals on the surface. Figure 2-1 shows the VSWIR spectra of the dust source minerals that are the focus of the EMIT measurements. Of particular interest for the EMIT radiative forcing objectives are the iron oxide minerals hematite and goethite that are strongly absorbing in the 400 to $1000 \mathrm{~nm}$ region that includes the solar peak signal.

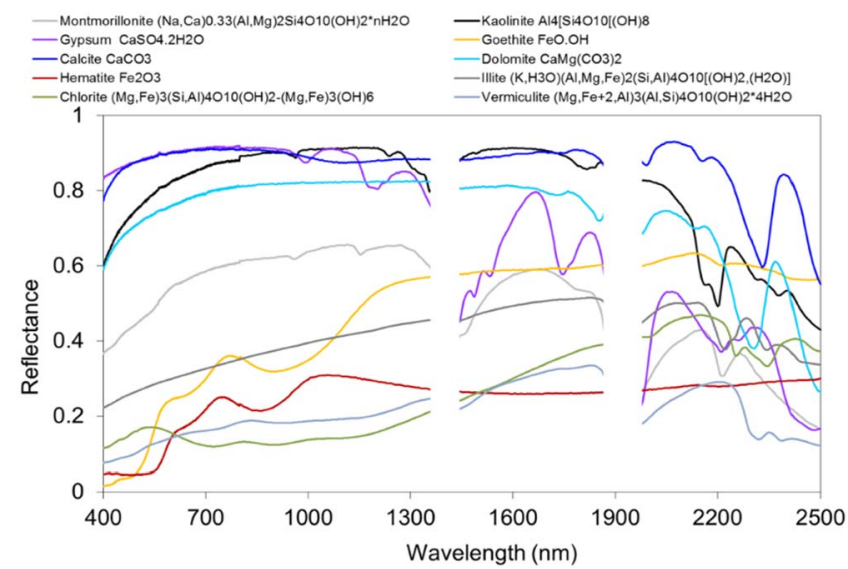

Figure 2-1. Reflectance spectra in the VSWIR range of the EMIT designated dust source minerals showing the distinct spectral signature that is related to their composition.

The arid land mineral dust source regions of the Earth have been identified by analysis of the estimated frequency of occurrence of mineral dust aerosols in the atmosphere without specific compositional knowledge (Ginoux et al., 2012). These dust source regions (Figure 2-2) lie below the orbit of the ISS. In another study, Chudnovsky et al, 2009 have demonstrated that the minerology of the dust emitted from the Bodélé Depression in Chad, as well as from the surface source, can be spectrally identified using the former imaging spectrometer, Hyperion, onboard the EO-1 spacecraft and the USGA spectral library archive.

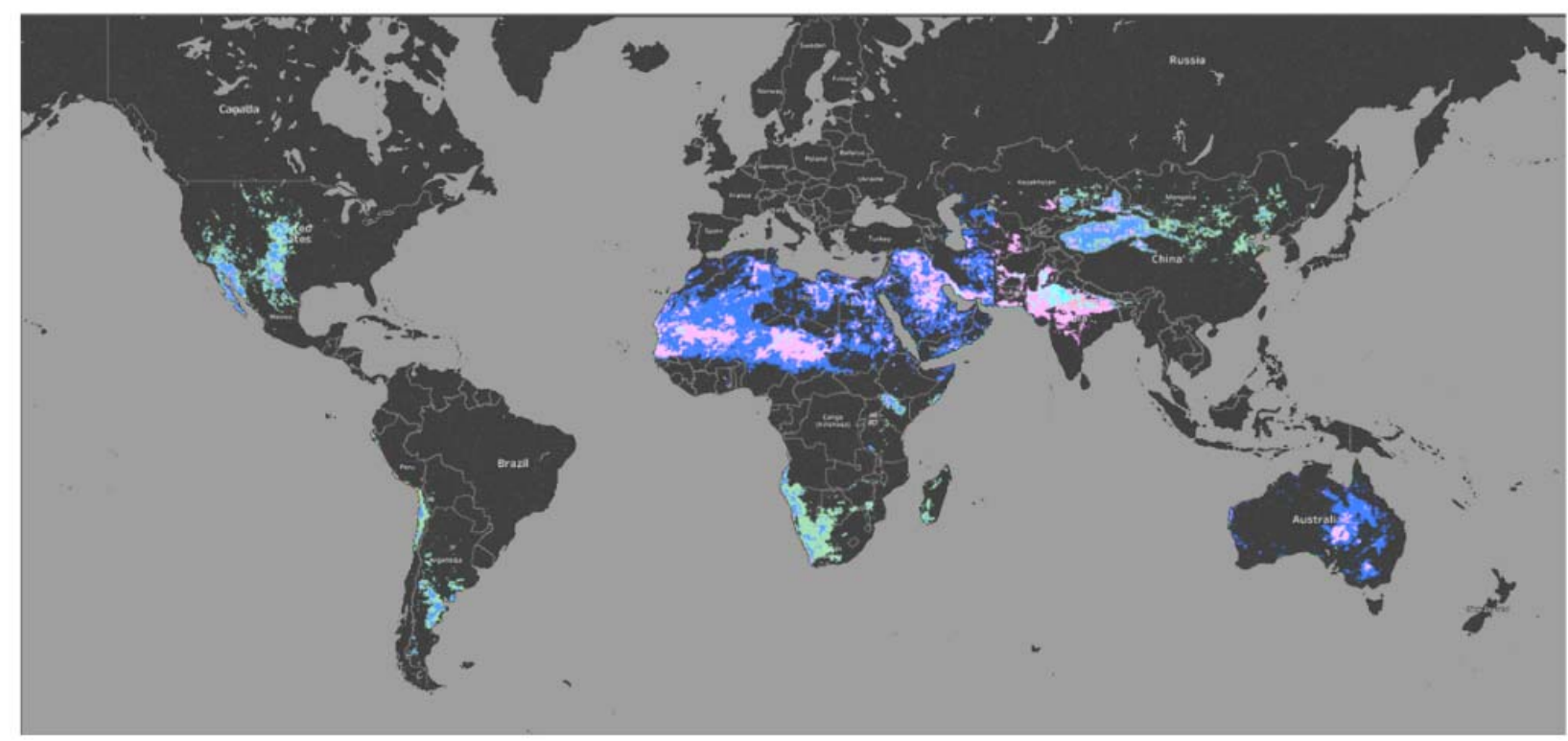

Figure 2-2. Location of the Earth's mineral dust source regions as inferred from MODIS frequency of occurrence of 
dust events (Ginoux et al., 2012). These are observable from the orbit of the ISS.
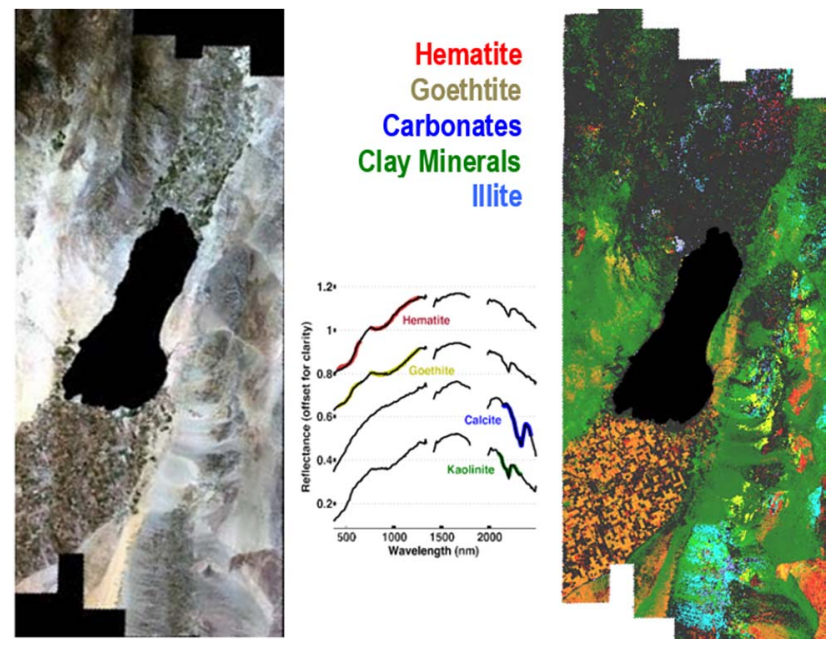

Figure 2-3. Demonstration of the EMIT mineral spectral fitting approach with high altitude airborne imaging spectrometer measurements of the Salton Sea, CA mineral dust source region.
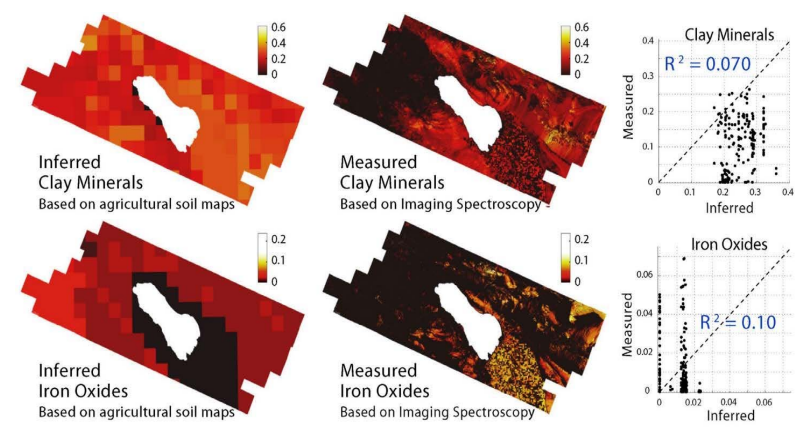

Figure 2-4. Comparison of existing clay and iron oxide ESM initialization products at Salton Sea with corresponding field validated AVIRIS 2014 imaging spectroscopy products shows that existing ESM products poorly predict iron oxide and clay occurrences.

The EMIT science objectives are enabled by accurately updating surface mineralogy of arid land regions with imaging spectroscopy observations from the ISS. To demonstrate this approach, an existing high altitude $(20 \mathrm{~km})$ airborne imaging spectrometer data set acquired by the Airborne Visible/Infrared Imaging Spectrometer (AVIRIS) over the Salton Sea, CA dust source area was analyzed. Figure 2-3 shows the AVIRIS natural color image, a set of example spectra with spectral fitting region highlighted, and the resulting surface mineral map. The predicted surface mineralogy was validated with field measurements. The spectroscopy-derived mineralogy was then compared with the existing mineral products used to currently initialize ESMs for the Salton Sea region. The comparison is shown in Figure 2-4. There is poor agreement between the validated imaging spectroscopy determined mineralogy and the current mineralogy used to initialize ESMs.

\section{KEY MisSION REQUIREMENTS}

From the EMIT science goal and objectives, highlevel science and instrument requirements were developed to provide the foundation for the full set of requirements needed to develop and implement the EMIT instrument and mission. The science requirements for EMIT are given below.

a) To determine mineral composition for the required dust source minerals with diagnostic signatures (hematite, goethite, illite, vermiculite, calcite, dolomite, montmorillonite, kaolinite, chlorite, and gypsum), the EMIT investigation shall measure spectra in the visible to short wavelength infrared range.

b) Acquire measurements over the arid dust source regions that drive radiative forcing between $\pm 50^{\circ}$ latitude including those within Africa, Asia, North America, Australia, and South America, and adjacent lands that are potential future mineral dust source regions.

c) To measure mineral composition in heterogeneous dust source regions as well as in adjacent lands with mixed vegetation and exposed mineral soils, the EMIT investigation shall sample spatial scales capable of assessing mineral exposures $\leq 1$ hectare.

d) To constrain the sign and magnitude of dustrelated radiative forcing and predict the increase or decrease of available dust sources under future climate scenarios, the EMIT investigation shall acquire sufficient observations within 1 year from In-Orbit Checkout (IOC) to provide spectroscopically-derived mineral compositions to initialize ESM simulations.

e) Record, validate, publish, and deliver science data records and calibrated geophysical data products to the NASA-selected DAAC for use by the scientific community.

From these science requirements, a corresponding set of high-level science instrument requirements 
Image acquisition is performed in push-broom fashion without the use of any pointing mechanism.

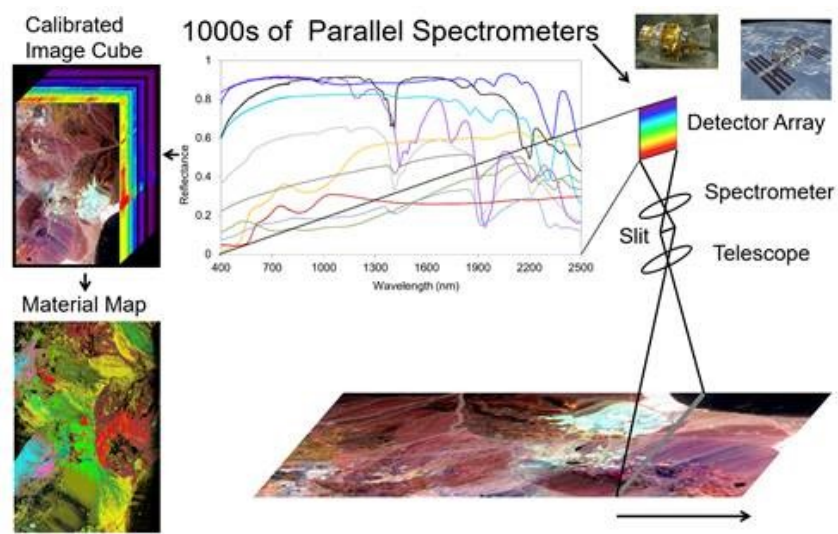

Figure 3-1. EMIT instrument approach for an optically fast VSWIR Dyson imaging spectrometer on the ISS to measure the Earth's mineral dust source regions.

\subsection{Optical}

Recent imaging spectrometer developments at JPL are based on Offner and Dyson design forms (Mouroulis, et al. 2000; Mouroulis et al., 2018). These have good optical throughput and enable excellent spectral and spatial uniformity that is required for high fidelity spectroscopy and enables the use of the most advanced spectroscopic algorithms. The optical design of the EMIT imaging spectrometer uses the Dyson form with an optical throughput of $\mathrm{F} / 1.8$ and is shown in Figure 4-1. Broadband light enters the slit, then passes through the refractive element to the grating where the light is spectrally dispersed and then returns through the refractive element to the order sorting filter and detector array. The EMIT spectrometer measures the VSWIR spectral range from $380 \mathrm{~nm}$ to $2500 \mathrm{~nm}$ with $7.4 \mathrm{~nm}$ spectral sampling. There are 1240 illuminated cross-track elements in the slit direction. This spectrometer is enabled by the large concave shaped-blaze grating that is fabricated at the JPL Microdevices Laboratory.

To deliver the required imaging performance for EMIT from the ISS, the spectrometer is configured with a two-mirror telescope shown in Figure 4-2. This telescope supports the $11^{\circ}$ cross-track field of view required by EMIT and the 150 microradians spatial sampling in the along and cross-track directions. Together the Dyson spectrometer and the two-mirror telescope deliver the spectral, radiometric, spatial, and uniformity observation characteristics required by EMIT.

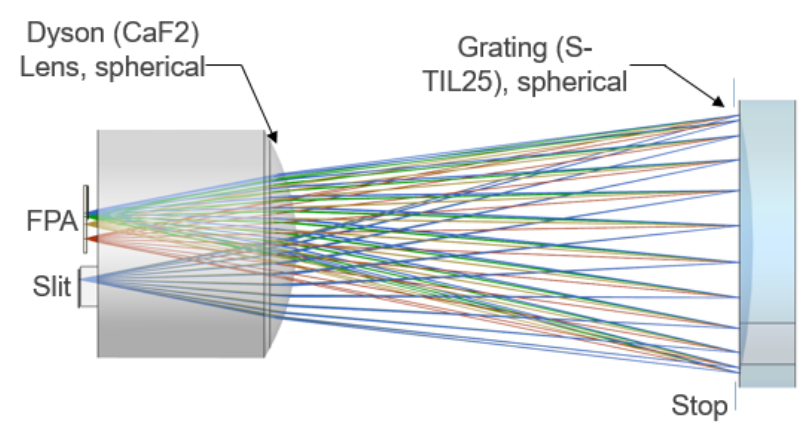

Figure 4-1. EMIT VSWIR Dyson spectrometer covering the spectral range from $380 \mathrm{~nm}$ to $2500 \mathrm{~nm}$ with $7.4 \mathrm{~nm}$ sampling. The spectrometer illuminates 1240 crosstrack elements of the HgCdTe 1280 x 480 detector array with 30-micron pitch.

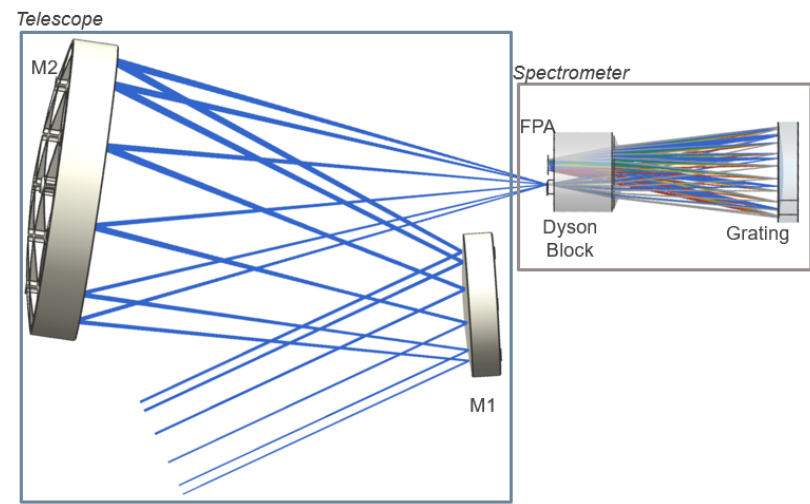

Figure 4-2. EMIT imaging spectrometer configured with the all reflective two mirror telescope and Dyson full range VSWIR spectrometer.

\subsection{Mechanical}

The EMIT imaging spectrometer is planned to operate from site- 8 on the ExPRESS Logistics Carrier (ELC) number 1 on the ISS. Interface with this site is provided by the ExPRESS payload adapters (ExPA) (aka FRAM). Figure 4-3 shows the mechanical configuration of the EMIT telescope and spectrometer on the Optical Bench Assembly (OBA) attached to the FRAM. Considerable engineering effort has been applied to meet the requirements for this interface as well as to accommodate the environments that will be encountered by EMIT from launch to installation and operation. 


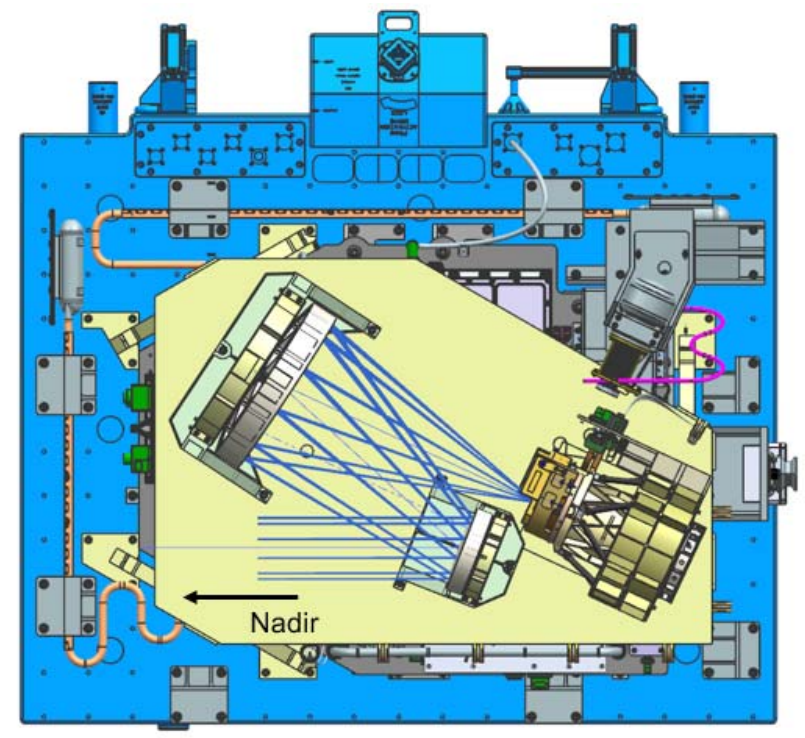

Figure 4-3. The pre-PDR mechanical configuration of the EMIT telescope and spectrometer on ISS FRAM interface structure. Closeout panels, baffling, and blanketing not shown.

\subsection{Electrical and Software}

EMIT electronic components are located on the avionics bench below the optical bench. The configuration of the electronic elements is shown in Figure 4-4. Light enters the EMIT instrument and is recorded by the CHROMA (Teledyne Imaging Sensors, Inc.) $\mathrm{HgCdTe}$ detector array that is sensitive to light from 380 to $2500 \mathrm{~nm}$. The CHROMA detector array is controlled and the signals digitized by the Focal Plane Interface Electronics (FPIE-A), which also performs the signal digitization. The FPIE-A interfaces to the CHROMA with a flex print cable and buffer board to ensure high signal quality. A dedicated low noise Power Supply Unit (PSU) powers the FPIEA.

A separate unit termed the FPIE-D handles all the high rate digital data and a number of other critical functions. The FPIE-D includes a large solid-state data recorder (SSDR), advanced spectroscopic algorithms for cloud detection, screening, and data compression, and is the primary interface to the ISS for command, telemetry and science data transfer. The raw data rate of EMIT is 1.6 gigabits per second. The SSDR has a capacity of 440 gigabytes, allowing for long-term on-board storage of compressed and processed science data. A separate electronic unit termed the ATOM supports housekeeping and temperature control. The cryocooler control electronics provide the power and control for the Thales Inc. 9310 pulse-tube cryocooler. The EMIT Power Conditioning Electronics (PCE) receives 120 volts from the ISS and delivers the required power to all the EMIT electronic elements. Additionally, there are survival heater and temperature sensors that interface directly to the ISS.

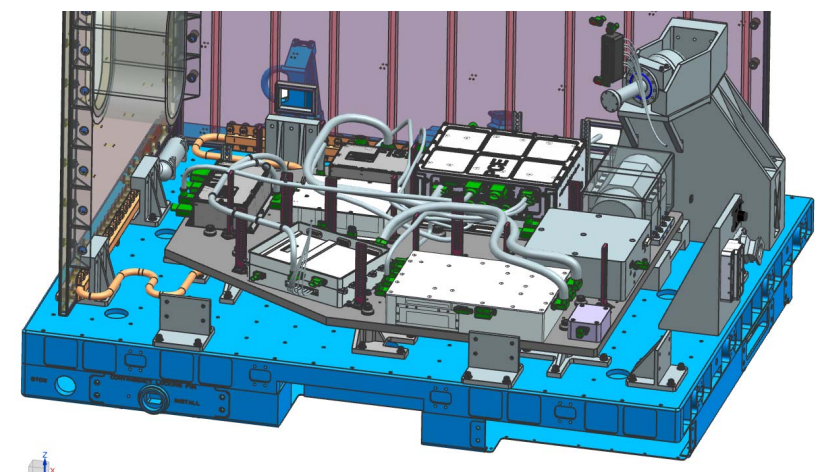

Figure 4-4. EMIT electronics bench that includes power conditioning, detector array control, high data rate processing, buffering, ISS interface, and thermal control. Closeout panels, baffling, and blanketing not shown.

\subsection{Thermal}

EMIT is a cryogenic VSWIR imaging spectrometer with a $2500 \mathrm{~nm}$ long wavelength cutoff $\mathrm{HgCdTe}$ detector array. To enable the EMIT spectroscopic measurements, the CHROMA detector array temperature is controlled to $155 \mathrm{~K}$ and the spectrometer to $240 \mathrm{~K}$. The cooling for the EMIT detector and spectrometer is provided by a single Thales 9310 pulse tube cryocooler with separate optimized thermal conductors. The heat from the cryocooler and all of the electronics is rejected to space from EMIT with via two radiators. Figure 4-5 shows the EMIT instrument and the two large radiators facing in the wake and nadir directions. This has been a significant engineering challenge for EMIT and requires the use of Variable Conductance Heat Pipes (VCHPs) and other specialized thermal hardware. The EMIT thermal design also accommodates the challenges of the full range of power and unpowered environments through the phases of launch, transport, installation, and operations. 


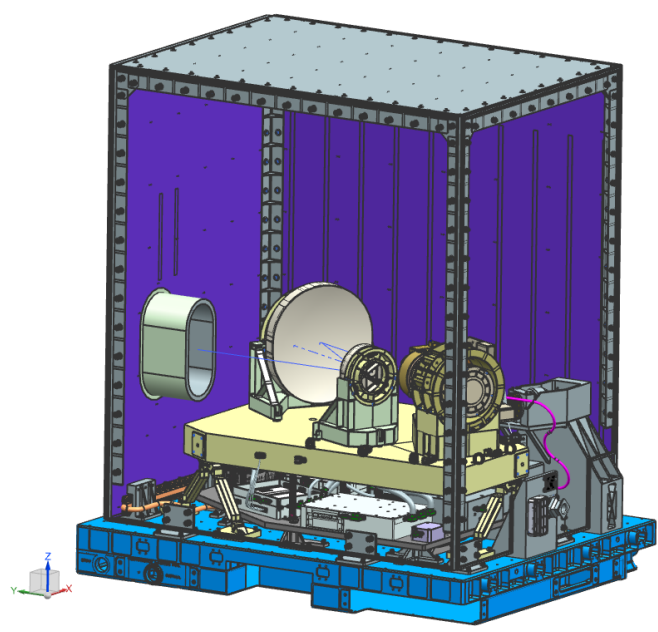

Figure 4-5. EMIT instrument configured with nadir and wake radiators to dissipate heat from the cryocooler and all electronic elements. Closeout panels, baffling, and blanketing not shown.

\subsection{Integration, Test and Calibration}

To complete the development of the EMIT instrument the optical, mechanical, electrical, and thermal elements must be integrated, tested and calibrated. This process includes verifying the performance of the subsystems as they are delivered as well as the intermediate test of performance as the instrument is being assembled. Once assembled, EMIT will pass through appropriate dynamic and electromagnetic testing to confirm performance with margin through relevant environments. Calibration is another key element in the integration and test phase. These measurements are used to determine the spectral, radiometric, spatial, and uniformity calibration of EMIT such that the recorded signals can be converted to scientifically usable measurements with units, response functions, and corresponding uncertainties at levels that meet EMIT requirements. Following final performance verification, EMIT will be delivered to the launch site for transport to the ISS, installation, in-orbit checkout and to begin the operational phase of the EMIT mission.

\section{Mission Elements and Planned OPERATIONS}

EMIT will be ready for a launch to the ISS in late 2021. Following arrival at the ISS, EMIT will be robotically transferred and installed on ELC-1 site-
8. EMIT will then enter a 30-day period of in-orbit checkout to confirm the instrument is operating properly and ready to collect the imaging spectroscopy measurements required for the science objectives. EMIT instrument operations on the ISS involve interaction with multiple NASA centers and elements within each center, as shown in Figure 5-1. At JPL, this effort is led by the EMIT Instrument Operation System (IOS). During project development, the responsibilities of IOS will be to: develop requirements, operations concept, and design; configuring GDS software tools for EMIT planning, command and telemetry; plan and configure GDS security, networks, and data storage; plan and perform IOS GDS V\&V and testing; and generate operations documents, processes, and procedures. During EMIT operations, the IOS will: plan observations (with input from science team); generate instrument activity schedule; generate, verify and validate instrument commands; transfer instrument commands to HOSC; deliver L0 and ephemeris data to SDS; monitor instrument health and status; perform instrument $\mathrm{H} / \mathrm{K}$ trend analyses; evaluate instrument performance; maintain instrument engineering data storage; maintain and operate instrument testbed; and respond to and resolve instrument anomalies. The EMIT IOS implementation leverages architecture exercised by two other JPL instruments currently operating on the ISS, ECOSTRESS and OCO-3.

The EMIT Science Data System (SDS) is the collection of software whose primary responsibilities are to convert science telemetry into derived data products through a pipeline process and to distribute science data products to the science community. The EMIT SDS draws from the experience of acquiring, calibrating and delivering imaging spectroscopy measurements and products for more than 20 years at the Jet Propulsion Laboratory. Key instruments that have been supported are AVIRIS-Classic, AVIRIS-Next Generation and Portable Remote Imaging Spectrometer (PRISM) (Mouroulis et al., 2012). This architecture was also used to support the NASA Discovery Moon Mineralogy Mapper mission (Pieters et al., 2009; Green, et al., 2011). The functional scope and architecture of the EMIT 
SDS is shown in Figure 5-2. The current processing capability of the SDS is supported by a high-performance compute cluster consisting of 32 compute nodes and more than 3 petabytes of storage. Responsibilities of the EMIT SDS will be to: manage data production; store and track input, output, and ancillary data; generate software modules for pipeline processing; adapt existing, functioning imaging spectrometer software module prototypes (for Level 1B through Level 2A data products); generate and distribute validated EMIT data products; ensure the system is capable of ingesting up to $140 \mathrm{~GB}$ of Level 0 data daily; handle output data products of $\sim 1 \mathrm{~TB}$ per day; manage the delivery of validated data products delivered to the LP DAAC for distribution to the public; support EMIT IOS and monitor instrument performance; generate instrument performance reports; generate quicklook images (RGB PNG images); distribute data products to EMIT Science Team; and support validation and verification activities performed by the EMIT Science Team.

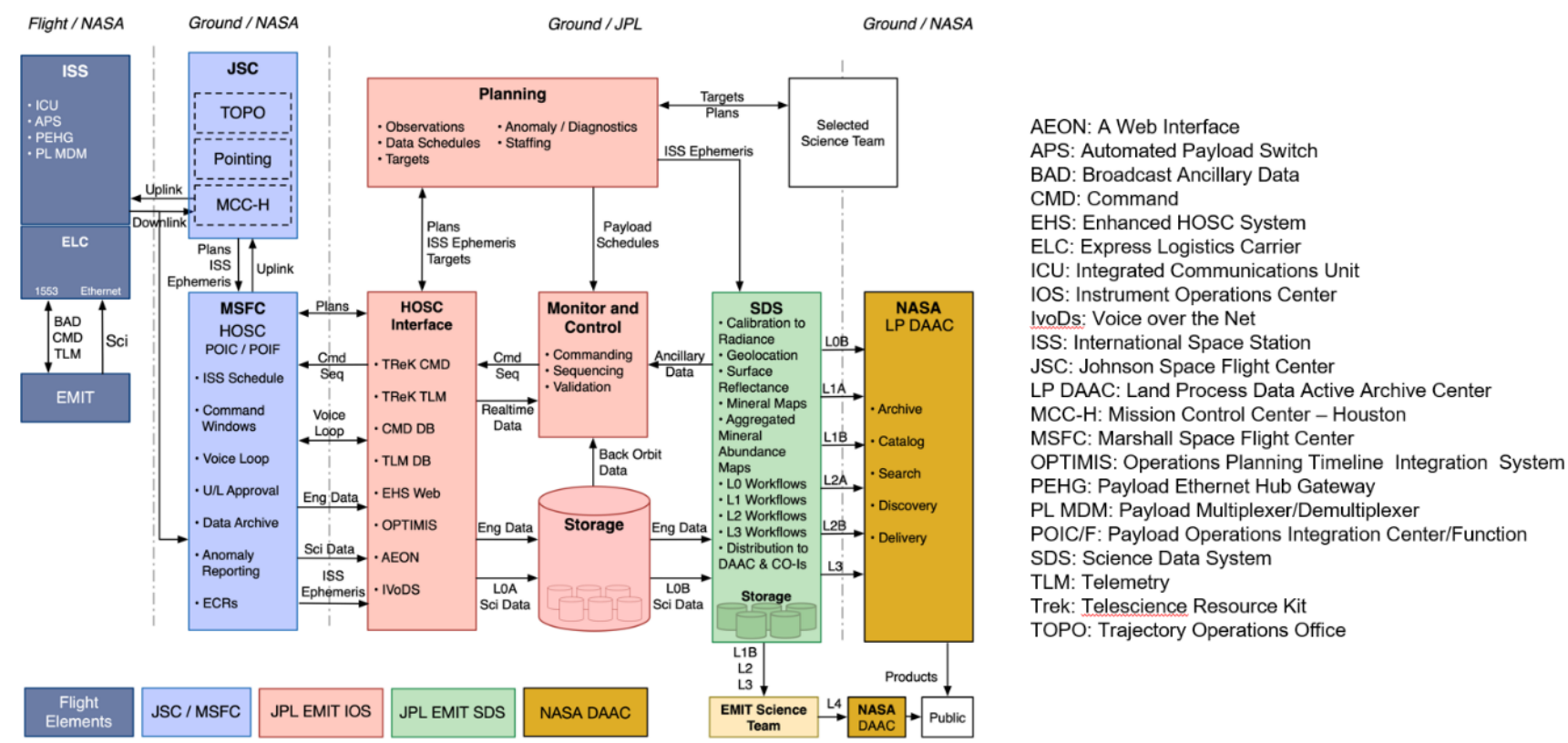

Figure 5-1. Key elements of the EMIT instrument operations and data system architecture.

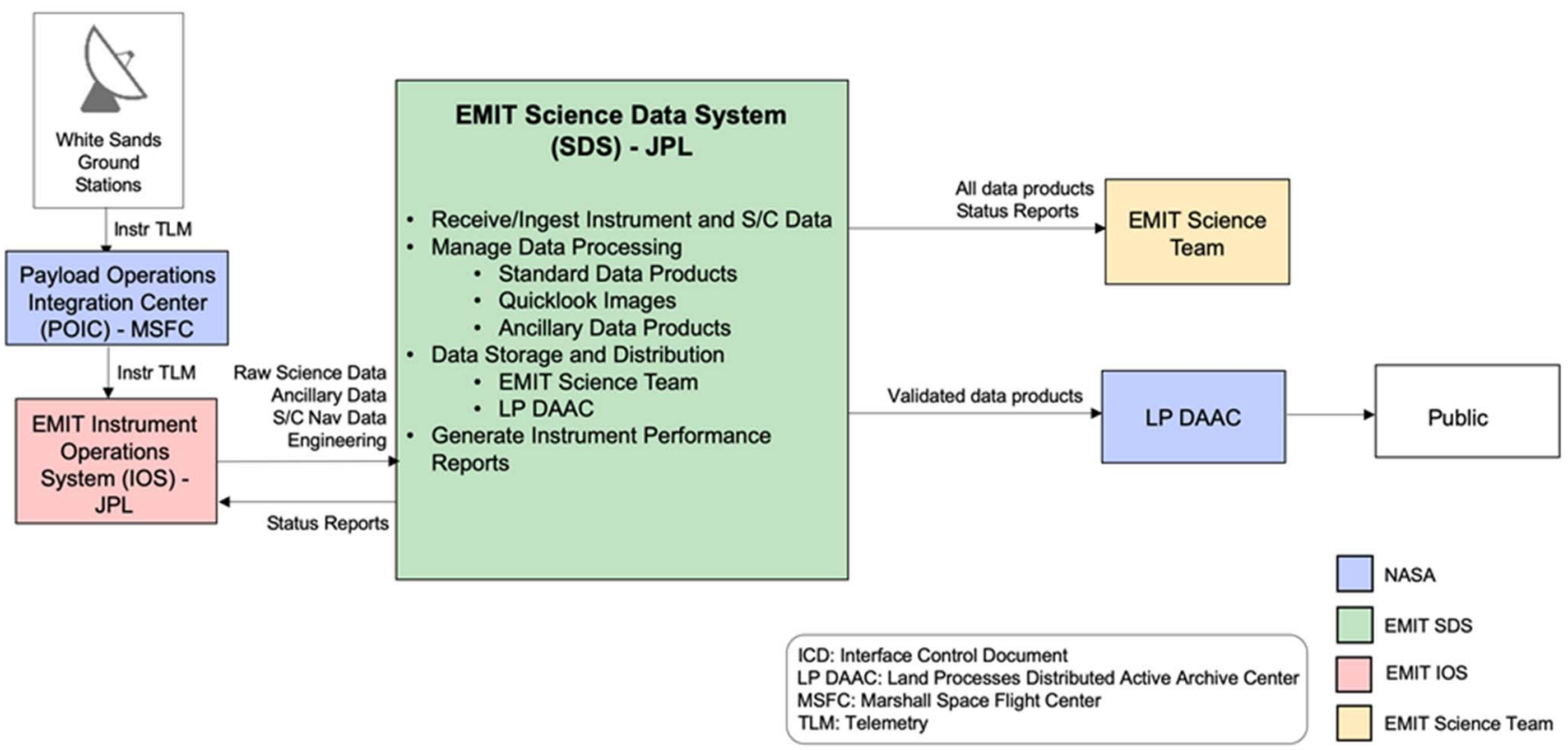

Figure 5-2. EMIT science data system role in the EMIT mission. 
Table 5-1. Data products generated in the Science Data System and with the science team to achieve the EMIT objectives.

\begin{tabular}{|l|l|}
\hline $\begin{array}{l}\text { Data } \\
\text { Product }\end{array}$ & Description \\
\hline Level 0 & Raw collected telemetry. \\
\hline Level 1a & $\begin{array}{l}\text { Reconstructed, depacketized, } \\
\text { uncompressed data, time referenced, } \\
\text { annotated with ancillary information } \\
\text { reassembled into scenes. }\end{array}$ \\
\hline Level 1b & $\begin{array}{l}\text { Level 1a data processed to sensor units } \\
\text { including geolocation and observation } \\
\text { geometry information. }\end{array}$ \\
\hline Level 2a & $\begin{array}{l}\text { Surface reflectance derived by screening } \\
\text { clouds and correction for atmospheric } \\
\text { effects. }\end{array}$ \\
\hline Level 3 & $\begin{array}{l}\text { Mineralogy derived from fitting } \\
\text { reflectance spectra, screening for non- } \\
\text { mineralogical components. }\end{array}$ \\
\hline Level 4 & $\begin{array}{l}\text { Gridded map of mineral composition } \\
\text { aggregated from level 2b with } \\
\text { uncertainties and quality flags. }\end{array}$ \\
\hline
\end{tabular}

The key EMIT data products delivered by the SDS are listed with descriptions in Table 5-1. These products are enabled by a long history of imaging spectrometer processing algorithms. Radiometric calibration converts the raw digitized values to at sensor radiance (Green et al., 1998, Chapman et al., 2018). Atmospheric correction compensates for the atmosphere and solar illumination geometry to deliver as surface reflectance product (Gao 1993, Thompson et al., 2015, 2018, 2019). The Tetracorder algorithm (Clark et al., 2003) is used to determine surface mineral composition for the reflectance product. Existing cloud mask and vegetation analysis algorithms (Roberts et al., 1998, Okin et al., 2001, Dennison et al., 2016) will be used to provide ancillary products beyond the EMIT designated minerals. A band depth algorithm and aggregation will be used to upscale the full resolution EMIT products to the scales required by the ESMs. For the ESM analyses, EMIT will use the National Science Foundation's Community Earth System Model (CESM) models (coordinated at the National Center for Atmospheric Research, NCAR), as described in Scanza et al. (2015). The NASA Goddard Institute for Space Studies (GISS) Earth System Model E2.1 will also be used to calculate mineral composition and radiative forcing. Model E2.1 is an update of the GISS Model E2 (Schmidt et al. 2014), used by Perlwitz et al. (2015a, b) and Pérez et al. (2015, 2016) and participated in the coordinated experiments of Coupled Model Intercomparison Project 6. All products, including EMIT model runs for the science objectives, will be delivered to the Land Processes Distributed Active Archive Center (LP DAAC) for use by the broader science and applications community.

Following in-orbit checkout, EMIT will begin the one-year operations phase and begin collection of science data. A target list is prepared for each orbit based on the illumination conditions and the mineral dust source regions that occur below the ISS orbit. Figure 5-3 shows an expected typical orbit with dark signal level measured on the unilluminated portion of the orbit and mineral dust source targets collected under solar illumination conditions.

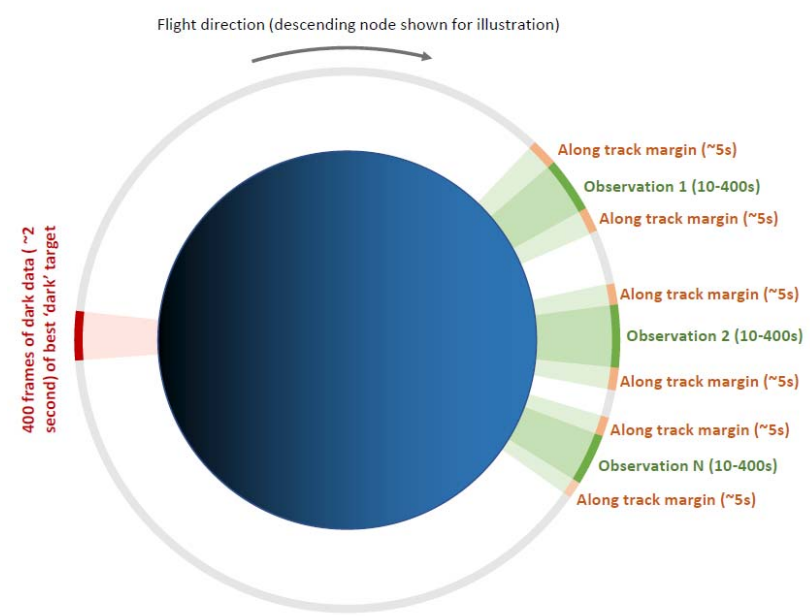

Figure 5-3. Example EMIT observation for one orbit collecting measurements over targeted dust source regions.

The combination of the ISS's precessing orbit, ground-illumination conditions, and fractionated science target masks results in an irregular image acquisition cycle over the course of a year with individual scenes varying in length from 15 seconds to nearly 600 seconds. Figure 5-4 shows the irregular cadence over the course of one simulated year. 


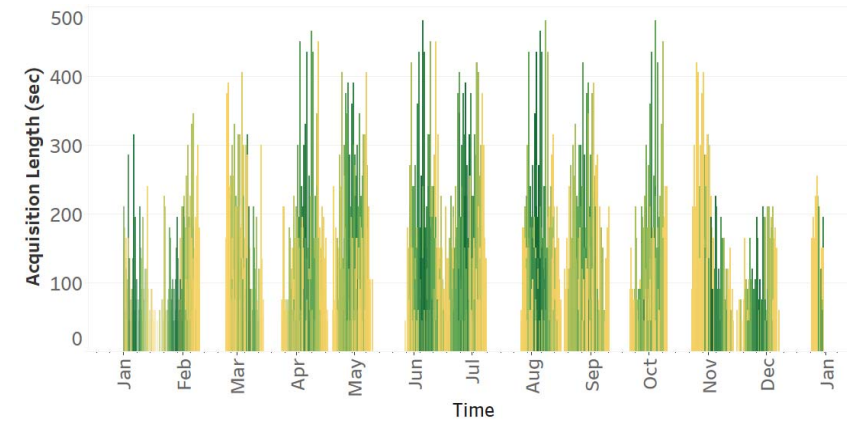

Solar Zenith .

Figure 5-4. Imaging strips of varying length are acquired over a calendar year. Gaps in acquisitions occur due to unfavorable observation geometry.
Figure 5-5 shows the expected coverage by EMIT after one year of observations from the ISS with excellent coverage of the Earth's mineral dust source regions and adjacent lands. Analysis with available cloud statistics and knowledge of the ISS orbit predicts EMIT will be capable of collecting the required spectroscopic observations within 6 months. This provides good margin with respect to the one of year planned operations on the ISS. These high-fidelity spectroscopic observations in conjunction with the SDS processing and science team provide the basis to achieve the science objectives that are the focus or the EMIT mission.

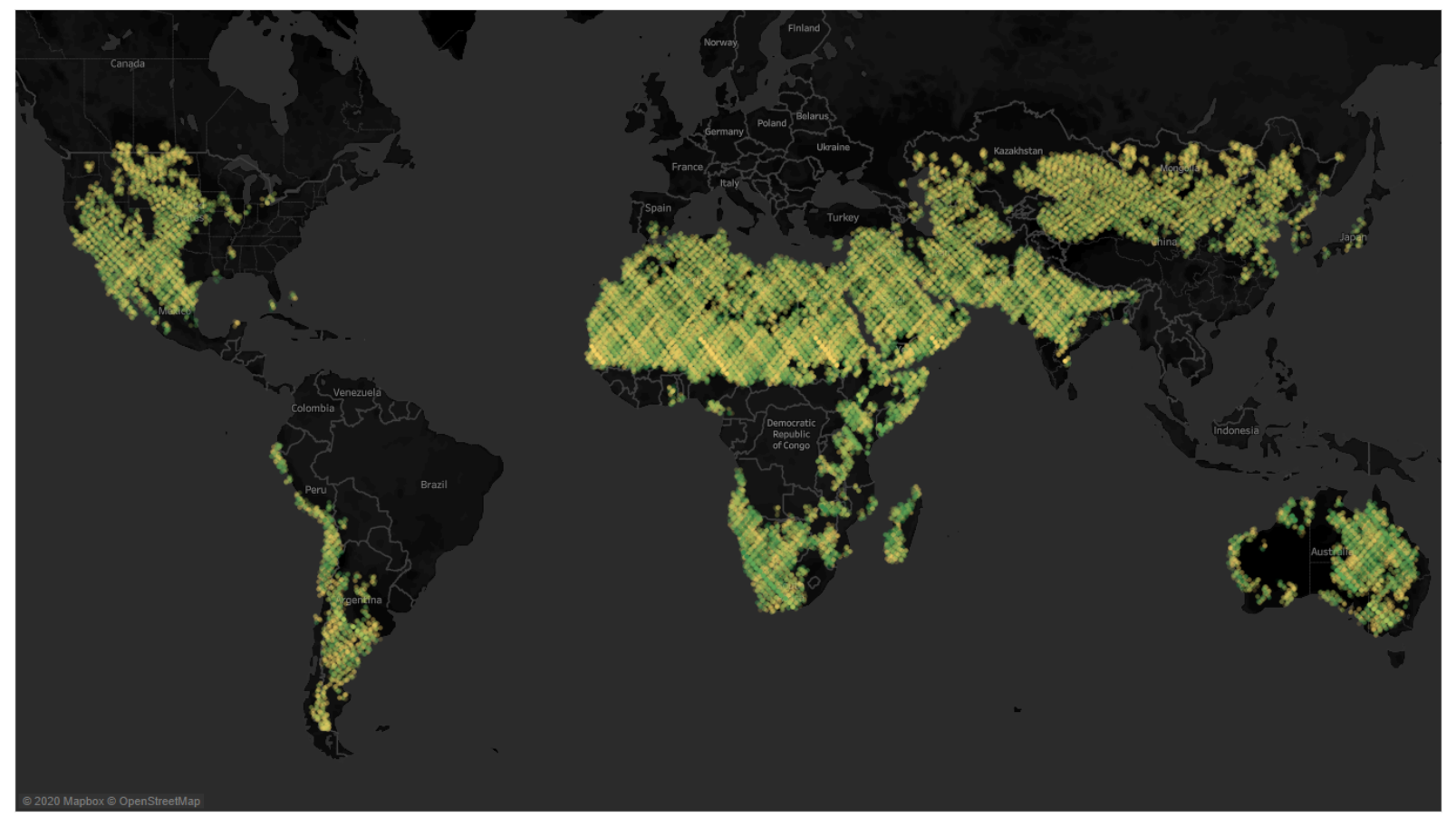

Figure 5-5. Depiction of the predicted coverage of the Earth's mineral dust source regions after one year of in-orbit operations on the ISS. Color is indicative of the acquisition illumination conditions from $0^{\circ}$ (green) to $45^{\circ}$ (yellow) solar zenith angle.

\section{SUMMARY AND CONCLUSIONS}

The EMIT science objectives are to reduce uncertainty in how mineral dust aerosols impact radiative forcing in the Earth system now and how that may change in the future. EMIT achieves these objectives by acquiring more than one billion direct spectroscopic observations of the Earth's arid land mineral dust source regions. The EMIT observations are enabled through development of the EMIT imaging spectrometer instrument that is a state-of-the-art VSWIR Dyson design with high throughput and excellent spectroscopic uniformity.
The full rigor of the NASA space instrument development process is being used across the disciplines of systems, optical, mechanical, electrical, integration and test, as well as instrument operation and the science data system. Following launch and in-orbit checkout, the EMIT measurements will be acquired with one year of operation on the ISS from ELC-1 site-8 that provides a nadir view to the Earth. The EMIT science team will validate the spectroscopic measurements and derived products and use the gridded mineral composition product to initialize 
the designated ESMs to achieve the EMIT science objectives. All measurements from EMIT will be delivered to the Land Process Distributed Active Archive Center and made available to the broad science and applications communities for additional investigations. At the end of the mission, EMIT will have delivered the most comprehensive imaging spectroscopy data set for the targeted arid regions of the Earth, advancing understanding of the impacts of dust on the Earth system.

\section{ACKNOWLEDGMENTS}

The authors gratefully acknowledge NASA and the Earth System Science Pathfinder program office as well as the broad set of contributors to the EMIT mission. A portion of this work was carried out at the Jet Propulsion Laboratory / California Institute of Technology, Pasadena, California, under contract with the National Aeronautics and Space Administration.

\section{REFERENCES}

Boucher, O., D. Randall, P. Artaxo, C. Bretherton, G. Feingold, P. Forster, V.-M. Kerminen, Y. Kondo, H. Liao, U. Lohmann, P. Rasch, S. Satheesh, S. Sherwood, B. Stevens, and X.-Y. Zhang (2013). Chapter 7: Clouds and Aerosols, Climate Change 2013: The Physical Science Basis: Contribution of Working Group I to the Fifth Assessment Report of the Intergovernmental Panel on Climate Change, Stocker, T., D. Qin, G.-K. Plattner, M. Tignor, S. Allen, J. Boschung, A. Nauels, Y. Xia, V. Bex, and P. Medigley, eds., Cambridge University Press, 573-657. ISBN:978-1-107-05799.

Chapman, J., Thompson, D. R., Helmlinger, M. C., Eastwood, M. L., Bue, B. D., Geier, S., Green, R. O., Lundeen, S. R., Olson-Duvall, W. (2019). Spectral and Radiometric Calibration of the Next Generation Airborne Visible Infrared Spectrometer (AVIRIS-NG). Remote Sensing, accepted 2019.

Chudnovsky, A., Ben Dor, E., Kostinski, A. B., \& Koren, I. (2009). Mineral content analysis of atmospheric dust using hyperspectral information from space. Geophysical Research Letters, 36(15).

Claquin, T., M. Schulz, and Y. Balkanski (1999). Modeling the mineralogy of atmospheric dust sources, J. Geophys. Res., 104, 22, 243-256. doi:10.1029/1999JD900416.

Dennison, P. E., R. F. Kokaly, C. S. T. Daughtry, D. A. Roberts, D. R. Thompson, J. Q. Chambers, P. L.
Nagler, G. S. Okin, and P. Scarth. "Estimating Achievable Accuracy for Global Imaging Spectroscopy Measurement of Non-Photosynthetic Vegetation Cover." In AGU Fall Meeting Abstracts. 2016.

Gao, B.-C., K. Heidebrecht, and A. Goetz (1993a). Derivation of scaled surface reflectances from AVIRIS data, Remote Sens. of Environ., 44, 165178. doi:10.1016/00344257(93)90014-O.

Ginoux, P., J. Prospero, T. Gill, N. Hsu, and M. Zhao (2012). Global scale attribution of anthropogenic and natural dust sources and their emission rates based on MODIS deep blue aerosol products, Rev. Geophy., 50. doi:10.1029/2012RG000388.

Green, R. O., et al. (1998), Imaging spectroscopy and the Airborne Visible Infrared Imaging Spectrometer (AVIRIS), Remote Sens. Environ., 65(3), 227-248, doi:10.1016/S00344257(98)00064-9.

Green, RO, The Moon Mineralogy Mapper (M3) imaging spectrometer for lunar science: Instrument description, calibration, on-orbit measurements, science data calibration and on-orbit validation," JOURNAL OF GEOPHYSICAL RESEARCH, VOL. 116, E00G19, 31 PP., 2011

Journet, E., Y. Balkanski, and S. Harrison (2014). A new data set of soil mineralogy for dust cycle modeling, Atmos. Chem. Phys., 14, 3801-3816. doi:10.5194/acp-14-3801-2014.

Mahowald, N. M. M., Kloster, S., Engelstaedter, S., Moore, J. K. K., Mukhopadhyay, S., McConnell, J. R. R., Albani, S., Doney, S. C. C., Bhattacharya, A., Curran, M. A. J. A. J., Flanner, M. G. G., Hoffman, F. M. M., Lawrence, D. M. M., Lindsay, K., Mayewski, P. A. A., Neff, J., Rothenberg, D., Thomas, E., Thornton, P. E. E. and Zender, C. S. S.: Observed 20th century desert dust variability: impact on climate and biogeochemistry, Atmos. Chem. Phys., 10(22), 10875-10893, doi:10.5194/acp-10-10875-2010, 2010.

Mahowald, N. N. M., and Kiehl, L. M. L.: Mineral aerosol and cloud interactions, Geophys. Res. Lett., 30(9), 10.109/2002GL016762, 2003.

Miller, R.L., I. Tegen, and J. Perlwitz (2004). Surface radiative forcing by soil dust aerosols and the hydrologic cycle, J. Geophys. Res., 109, D4, 203. doi:10.1029/2003JD004085.

Mouroulis, Pantazis, Byron E. Van Gorp, Robert O. Green, Michael Eastwood, Daniel W. Wilson, Brandon Richardson, and Heidi Dierssen. "The portable remote imaging spectrometer (PRISM) coastal ocean sensor." In Optical Remote Sensing of the Environment, pp. RM2E-5. Optical Society of America, 2012. 
Myhre, G., D. Shindell, F.-M. Bréon, W. Collins, J. Fuglestvedt, J. Huang, D. Koch, J.-F. Lamarque, D. Lee, B. Mendoza, T. Nakajima, A. Robock, G. Stephens, T. Takemura and H. Zhang (2013). Chapter 8: Anthropogenic and Natural Radiative Forcing, Climate Change 2013: The Physical Science Basis: Contribution of Working Group I to the Fifth Assessment Report of the Intergovernmental Panel on Climate Change, Stocker, T., D. Qin, G.-K. Plattner, M. Tignor, S. Allen, J. Boschung, A. Nauels, Y. Xia, V. Bex and P. Midgley, eds., Cambridge University Press, 659740. ISBN: 978-1-107-05799.

Okin, Gregory S., Dar A. Roberts, Bruce Murray, and William J. Okin. "Practical limits on hyperspectral vegetation discrimination in arid and semiarid environments." Remote Sensing of Environment 77, no. 2 (2001): 212-225.

Perlwitz, J., C. Perez Garcia-Pando, and R. Miller (2015a). Predicting the mineral composition of dust aerosols - Part 1: Representing key processes, Atmos. Chem. Phys. Discuss., 15, 34933575. doi:10.5194/acpd-15-3493-2015.

Perlwitz, J., C. Perez Garcia-Pando, and R. Miller (2015b). Predicting the mineral composition of dust aerosols - Part 2: Model evaluation and identification of key processes with observations, Atmos. Chem. Phys. Discuss., 15, 3577-3627. doi: 10.5194/acpd-15-35772015.

Pérez C, Nickovic S, Pejanovic G, Baldasano JM, Özsoy E (2006) Interactive dust-radiation modeling: a step to improve weather forecasts. J Geophys Res 111: D16206. doi:10.1029/ 2005JD006717

Pérez García-Pando, C., R. L. Miller1, J. P. Perlwitz, J. Kok, R. Scanza, N. Mahowald (2015). Dust Composition in Climate Models: Current Status and Prospects. AGU Fall Meeting 2015. San Francisco.

Pérez García-Pando, C., R.L. Miller, J.P. Perlwitz, S. Rodríguez, and J.M. Prospero (2016) Predicting the mineral composition of dust aerosols: Insights from elemental composition measured at the Izaña Observatory. Geophys. Res. Lett., 43, no. 19, 10520-10529, doi:10.1002/2016GL069873.

Roberts, Dar A., M. Gardner, Rick Church, S. Ustin, G. Scheer, and R. O. Green. "Mapping chaparral in the Santa Monica Mountains using multiple endmember spectral mixture models." Remote sensing of environment 65, no. 3 (1998): 267-279.

Rosenfeld, D., Rudich, Y. and Lahav, R.: Desert dust suppressing precipitation: a possible desertification feedback loop, Proc. Natl. Acad. Sci. U. S. A.,
98(11), 5975-5980, 2001.

Schmidt, G., M. Kelley, L. Nazarenko, R. Ruedy, G. Russell, I. Aleinov, M. Bauer, S. Bauer, M.

Bhat, R. Bleck, V. Canuto, Y.-H. Chen, Y. Cheng, T. Clune, G. Faluvegi, J. Hansen, R. Healy, and N. Kiang (2014). Configuration and assessment of the GISS ModelE2 contributions to the CMIP5 archive, J. Adv. Model. Earth Syst., 6, 141-184.

doi:10.1002/2013MS000265.

Scanza, R., N. Mahowald, S. Ghan, C. Zender, J. Kok, X. Liu, Y. Zhang, and S. Albani (2015). Dependence of dust radiative forcing on mineralogy in the Community Atmosphere Model, Atmos. Chem. Phys., 15, 537-561. doi:10.5194/acp-15-537-2015.

Thompson, David R; Gao, Bo-Cai; Green, Robert O; Roberts, Dar A; Dennison, Philip E; Lundeen, Sarah R; "Atmospheric correction for global mapping spectroscopy: ATREM advances for the HyspIRI preparatory campaign," Remote Sensing of Environment, 167, 64-77, (2015)

Thompson, David R; Natraj, Vijay; Green, Robert O; Helmlinger, Mark C; Gao, Bo-Cai; Eastwood, Michael L; "Optimal estimation for imaging spectrometer atmospheric correction," Remote sensing of environment, 216, 355-373, (2018)

Thompson, David R; Babu, KN; Braverman, Amy J; Eastwood, Michael L; Green, Robert O; Hobbs, Jonathan M; Jewell, Jeffrey B; Kindel, Bruce; Massie, Steven; Mishra, Manoj; "Optimal estimation of spectral surface reflectance in challenging atmospheres," Remote Sensing of Environment, 232, 111258, (2019)

Vane, G., A. F. H. Goetz, and J. B. Wellman (1984), Airborne Imaging Spectrometer: A new tool for remote sensing, IEEE Trans. Geosci. Remote Sens., 22(6), 546-549.

Vane, Gregg, et al. "The airborne visible/infrared imaging spectrometer (AVIRIS)." Remote Sensing of Environment 44.2-3 (1993): 127-143.

Yoshioka, M., Mahowald, N. M., Conley, A. J., Collins, W. D., Fillmore, D. W., Zender, C. S. and Coleman, D. B.: Impact of desert dust radiative forcing on sahel precipitation: Relative importance of dust compared to sea surface temperature variations, vegetation changes, and greenhouse gas warming, J. Clim., 20(8), doi:10.1175/JCLI4056.1, 2007. 


\section{BIOGRAPHY}

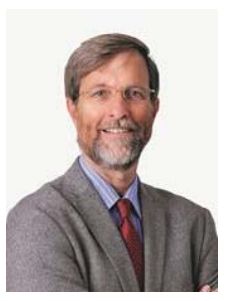

Robert O. Green is a Senior Research Scientist at the Jet Propulsion Laboratory with a 30 year science focus using advanced imaging spectroscopy. Among other roles, he is the Principal Investigator of the NASA Earth Venture mission, Earth Surface Mineral Dust Source Investigation (EMIT).

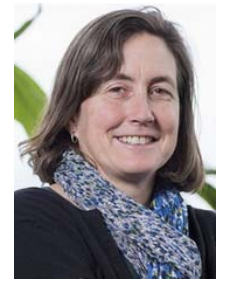

Natalie M. Mahowald is the Irving Porter Church Professor of Engineering in the Department of Earth and Atmospheric Sciences at Cornell University. Her research focuses on modeling and synthesizing observations to understand aerosol-climate and biogeochemistry interactions, and among other roles is the Deputy Principal Investigator of the NASA Earth Venture mission, Earth Surface Mineral Dust Source Investigation (EMIT).

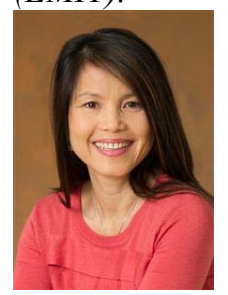

Charlene Ung has over 29 years of experience leading teams that have designed, built and tested key electronic components of aerospace satellites. In her current role as Project Manager at NASA's Jet Propulsion Laboratory, Charlene is managing the Earth Surface Mineral Dust Source Investigation (EMIT) project, an ISS payload.

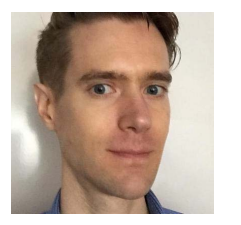

David R. Thompson is a Principal Research Technologist at the Jet Propulsion Laboratory, California Institute of Technology, who has published 80 journal articles in diverse areas of imaging spectroscopy and related remote sensing algorithms. He is Instrument Scientist for NASA's EMIT and Lunar Trailblazer missions, and Investigation Scientist for NASA's AVIRIS imaging spectrometer investigation.

Matthew Bennett has been a systems engineer at the Jet Propulsion Laboratory for 10 years. He is currently serving as the Project Systems Engineer on the Orbiting Carbon Observatory 3 (OCO-3) and the Earth Surface Mineral Dust Source Investigation (EMIT) missions.

Natalie Blackway is the Information and Configuration Management Engineer (ICME) for the Earth Surface Mineral Dust Source Investigation (EMIT) project. She has over 15 years of experience providing ICME support for flight projects.

Christine L. Bradley is an Optical Engineer at the Jet Propulsion Laboratory with a background in spectropolarimetry. She is currently the Optics Lead of the NASA Earth Venture mission, Earth Surface Mineral Dust Source Investigation (EMIT).

Pam Clark has been with the Jet Propulsion Laboratory since 2007. She is an experienced project schedule analyst with an extensive background in large-scale aerospace and military programs. Before joining the Earth Surface
Mineral Dust Source Investigation (EMIT) project, she supported Mars Science Laboratory and Mars 2020.

Jeff Cha is a thermal engineer at the Jet Propulsion Laboratory with a 16 year of experience on space systems. He is currently the Thermal Lead of the NASA Earth Venture mission, Earth Surface Mineral Dust Source Investigation (EMIT).

Roger N. Clark is a Senior Scientist at the Planetary Science Institute with 40 years of experience in spectroscopy, imaging, and imaging spectroscopy analysis to map compounds throughout the Solar System, including mapping minerals and ecosystems on the Earth. Dr. Clark has been a science team member on multiple NASA spacecraft missions and his role as a science team Co-I on EMIT includes identification and mapping of minerals with the data from the EMIT spectrometer.

Michael L. Eastwood is a Senior Engineer at the Jet Propulsion Laboratory with a 30 year focus in the optoelectronic, optomechanical, and system design aspects of advanced imaging spectrometers, including multiple airborne instruments such as AVIRIS-Classic, AVIRIS-Next Generation, MaRS, NEON NIS, MSS, Asner Lab's Global Airborne Observatory, and others.

Bethany L. EhImann is a Professor of Planetary Science at Caltech and Research Scientist at the Jet Propulsion Laboratory with research in infrared and imaging spectroscopy for surface composition across the solar system, particularly of secondary minerals and ices on Mars, Moon, and the asteroids. She is a Co-Investigator on EMIT and PI of the Lunar Trailblazer mission.

Paul Ginoux is a senior research scientist at NOAA Geophysical Fluid Dynamics Laboratory with two decades of atmospheric chemistry model development. He also make use of satellite data to evaluate his model results, and to produce global datasets, such a global inventory of dust sources.

Olga V. Kalashnikova is a Research Scientist at JPL, primarily working on applications of particle scattering theory and remote sensing observations to mapping aerosol properties using advance remote sensing instruments. Among other roles, she is the Co-Investigator of the NASA Earth Venture mission, Earth Surface Mineral Dust Source Investigation (EMIT) assisting with global atmospheric dust distributions and an atmospheric correction. She received the BS in physics from Kazakh State National University, and the MS in physics and PhD in astrophysical, planetary and atmospheric science from the University of Colorado at Boulder.

William (Bill) Kert has been assigned as the EMIT Project Acquisition Manager and is responsible for oversight of all subcontracting actions (subcontracts, purchase orders, loan agreements, etc.).

Didier Keymeulen is principal member of the technical staff at the Jet Propulsion Laboratory developing adaptive computing technology for intelligent, autonomous and adaptive instrument avionics.

Longlei $\mathbf{L i}$ is a postdoctoral researcher at Cornell University. He received the PhD degree from Georgia Institute of Technology at Atlanta in 2018. His research 
interests are in areas of the interaction of mineral dust with climate using numerical models at varied spatiotemporal scales, and remote sensing of atmospheric aerosols.

Sarah Lundeen is a Software Systems Engineer with 20 years of experience developing and managing NASA/JPL imaging spectrometer science data systems (SDS) for both airborne and spaceborne missions. Presently, Sarah is the SDS manager of the NASA Earth Venture mission, Earth Surface Mineral Dust Source Investigation (EMIT) and the Mapping Imaging Spectrometer for Europa (MISE) for NASA's Europa Clipper Mission.

Ron L. Miller is a Research Physical Scientist at the NASA Goddard Institute for Space Studies, where he studies dust aerosols and their interaction with climate.

Bogdan Oaida is a Systems Engineer at Jet Propulsion Laboratory. He has been the OPALS Project Systems Engineer over the entire lifecycle of the mission, including extended operations. He is currently the Deputy Project Systems Engineer for the Earth Surface Mineral Dust Source Investigation (EMIT).

Gregory S. Okin is a Professor and Chair of Geography at UCLA. He is a co-Investigator of the NASA Earth Venture mission, Earth Surface Mineral Dust Source Investigation (EMIT).

Alberto Ortega is a Project Business Manager (PBM) at the Jet Propulsion Laboratory. Recent experience in earth science includes being the PBM on OCO-3 (Orbiting Carbon Observatory), MAIA (Multi-Angle Imager for Aerosols), and EMIT (Earth Surface Mineral Dust Source Investigation).

Thomas H. Painter is a Senior Project Scientist at JIFRESSE/University of California, Los Angeles with a 25-year emphasis on cryosphere imaging spectroscopy and hydrology. His roles have included Principal Investigator of the NASA Airborne Snow Observatory.

Jack Pempejian is the Mechanical Lead of the NASA Earth Venture mission, Earth Surface Mineral Dust Source Investigation (EMIT). He has been at JPL since 2007 supporting flight projects including OCO3, ECOSTRESS, and the M2020 Helicopter.

Carlos Pérez García-Pando is an ICREA Research Professor and AXA Professor on Sand and Dust Storms at the Barcelona Supercomputing Center, where he leads the Atmospheric Composition Group. He is the Principal Investigator of the FRAGMENT campaign to study the mineral composition of dust and its impact upon climate.

Richard Purcell is an Instrument Electrical Engineer at the Jet Propulsion Laboratory with a 15-year engineering focus in the aerospace industry. Richard is the Avionics lead of the NASA Earth Venture mission, Earth Surface Mineral Dust Source Investigation (EMIT) project.

Vincent J. Realmuto is a Principal Scientist at the Jet Propulsion Laboratory with a 30-year research focus on the application of imaging spectroscopy to studies of volcanic and geothermal phenomena. His interest in the spectroscopy of particulate media, such as volcanic aerosol plumes or arid dust source regions, forms the intersection between his research and the EMIT project.
Amit Sen has over $35+$ years of experience working with NASA space programs dealing with Astrophysics, Heliophysics, Earth Observing, Deep Space and Technology missions. He is currently the Deputy Manager of Earth Systematic Missions Program Office at NASA's Jet Propulsion Laboratory in Pasadena California.

Lucas Shaw is a member of the EMIT opto-mechanical design team at the Jet Propulsion Laboratory.

Gregg A. Swayze is a Senior Research Geophysicist at the U.S. Geological Survey in Denver, Colorado. Since 1985, he has applied imaging spectroscopy to mineral exploration, mapping the mineralogy of Mars, and mitigating environmental problems. He also co-developed the widely used USGS spectral library.

Erik Thingvold is an opto-mechanical engineer at the Jet Propulsion Laboratory. He is the opto-mechanical lead of the NASA Earth Venture mission, Earth Surface Mineral Dust Source Investigation (EMIT).

Jason Zan is an Engineer with 15 years of experience at the Jet Propulsion Laboratory. He has performed many engineering roles during his time at JPL and is currently the I\&T Lead on the EMIT project. 